ly active or inactive assemblies. Phosphorylation of SRF may also be germane. Events that control the conversion between these two presumptive forms of the SRF complex will need to be clarified in order to understand Hopregulated cardiac growth. It is even more important to determine what SRF target genes are directly regulated by Hop. Given the opposing phenotypes in embryonic versus neonatal hearts of Hop-deficient mice, different target genes are presumed to be regulated by Hop, depending on developmental stage. It is, of course, possible that Hop regulates factors beyond SRF alone.

1. Olson, E.N., and Schneider, M.D. 2003. Sizing up the heart: development redux in disease. Genes Dev. 17:1937-1956.

2. Zhang, C.L., et al. 2002. Class II histone deacetylases act as signal-responsive repressors of cardiac hypertrophy. Cell. 110:479-488.

3. Carrozza, M.J., Utley, R.T., Workman, J.L., and Cote, J. 2003. The diverse functions of histone acetyltransferase complexes. Trends Genet. 19:321-329.

4. Schreiber, S.L., and Bernstein, B.E. 2002. Signaling network model of chromatin. Cell. 111:771-778.
5. Grewal, S.I., and Moazed, D. 2003. Heterochromatin and epigenetic control of gene expression. Science. 301:798-802.

6. Yao, T.P., et al. 1998. Gene dosage-dependent embryonic development and proliferation defects in mice lacking the transcriptional integrator p300. Cell. 93:361-372.

7. Baluchamy, S., Rajabi, H.N., Thimmapaya, R. Navaraj, A., and Thimmapaya, B. 2003. Repression of c-Myc and inhibition of G1 exit in cells conditionally overexpressing p300 that is not dependent on its histone acetyltransferase activity. Proc. Natl. Acad. Sci. U. S. A. 100:9524-9529.

8. Imai, S., Armstrong, C.M., Kaeberlein, M., and Guarente, L. 2000. Transcriptional silencing and longevity protein Sir2 is an NAD-dependent histone deacetylase. Nature. 403:795-800.

9. Chen, F., et al. 2002. Hop is an unusual homeobox gene that modulates cardiac development. Cell. 110:713-723.

10. Shin, C.H., et al. 2002. Modulation of cardiac growth and development by HOP, an unusual homeodomain protein. Cell. 110:725-735.

11. Wang, D.Z., et al. 2002. Potentiation of serum response factor activity by a family of myocardinrelated transcription factors. Proc. Natl. Acad. Sci. U. S. A. 99:14855-14860.

12. Miralles, F., Posern, G., Zaromytidou, A.I., and Treisman, R. 2003. Actin dynamics control SRF activity by regulation of its coactivator MAL. Cell. 113:329-342.

13. Chang, D.F., et al. 2003. Cysteine-rich LIM-only proteins CRP1 and CRP2 are potent smooth muscle differentiation cofactors. Dev. Cell. 4:107-118.

14. Kook, H., et al. 2003. Cardiac hypertrophy and histone deacetylase-dependent transcriptional repression mediated by the atypical homeodomain protein Hop. J. Clin. Invest. 112:863-871. doi:10.1172/JCI200319137.

15. Antos, C.L., et al. 2003. Dose-dependent blockade to cardiomyocyte hypertrophy by histone deacetylase inhibitors. J. Biol. Chem. 278:28930-28937.

16. Marks, P.A., Richon, V.M., Breslow, R., and Rifkind, R.A. 2001. Histone deacetylase inhibitors as new cancer drugs. Curr. Opin. Oncol. 13:477-483.

17. Sano, M., and Schneider, M.D. 2002. Still stressed out but doing fine: normalization of wall stress is superfluous to maintaining cardiac function in chronic pressure overload. Circulation. 105:8-10

18. Shioi, T., et al. 2003. Rapamycin attenuates load induced cardiac hypertrophy in mice. Circulation. 107:1664-1670.

19. Sano, M., et al. 2002. Activation and function of cyclin T-Cdk9 (positive transcription elongation factor-b) in cardiac muscle-cell hypertrophy. Nat. Med. 8:1310-1317.

20. Sepulveda, J.L., Vlahopoulos, S., Iyer, D., Belaguli, N., and Schwartz, R.J. 2002. Combinatorial expression of GATA4, Nkx2-5, and serum response factor directs early cardiac gene activity. J. Biol. Chem. 277:25775-25782.

21. Davis, F.J., Gupta, M., Camoretti-Mercado, B. Schwartz, R.J., and Gupta, M.P. 2003. Calcium/calmodulin-dependent protein kinase activates serum response factor transcription activity by its dissociation from histone deacetylase, HDAC4. Implications in cardiac muscle gene regulation during hypertrophy. J. Biol. Chem. 278:20047-20058.

\title{
Tracking autoimmune $T$ cells in diabetes
}

\section{David V. Serreze and Edward H. Leiter}

The Jackson Laboratory, Bar Harbor, Maine, USA

\begin{abstract}
Insulin-dependent diabetes mellitus is usually caused by the autoimmune destruction of pancreatic $\beta$ cells by T cells. Methodologies to track the development, migration, and functional activation of one class of such $\mathrm{T}$ cells (CD4 T cells) have been limited. However, it now appears that this limitation has been overcome (see the related article beginning on page 902).
\end{abstract}

\section{J. Clin. Invest. 112:826-828 (2003). doi:10.1172/JCI200319842.}

Type 1 diabetes, or insulin-dependent diabetes mellitus (IDDM), in humans and rodent models results from the $\mathrm{T}$ cell-mediated autoimmune destruction of pancreatic islet $\beta$ cells. Both MHC class I-restricted CD8 T cells and MHC class II-

\footnotetext{
Address correspondence to: Edward $\mathrm{H}$. Leiter, The Jackson Laboratory, 600 Main Street, Bar Harbor, Maine 04609, USA. Phone: (207) 288-6370; Fax: (207) 288-6079; E-mail: ehl@jax.org.

Conflict of interest: The authors have declared that no conflict of interest exists. Nonstandard abbreviations used: Insulindependent diabetes mellitus (IDDM); nonobese diabetic (NOD); $T$ cell receptor (TCR); nonobese resistant (NOR).
}

restricted CD4 $\mathrm{T}$ cells contribute to this pathogenesis. Methodologies to identify, quantify, and track such autoreactive $\mathrm{T}$ cells have been lacking, especially for the CD4 subset. This is an important issue for studies designed to monitor the efficacy of potential intervention protocols. Over the past several years, tetramer reagents have been introduced and utilized for the quantification and tracking of CD8 $\mathrm{T}$ cells. These tetramers are synthesized as fluorochrome-labeled complexes of MHC class I molecules to which the appropriate peptide antigen has been bound. However, it has been difficult to fold complexes of MHC class II molecules for similar identification of antigen-specific CD4 T cells.

In this issue of the JCI, an article by Stratmann and colleagues (1) introduces an exciting new tetramer technology that allows a particular set of diabetogenic CD4 T cells to be quantified and tracked. Specifically, these authors utilized the nonobese diabetic (NOD) mouse model of IDDM wherein the unusual murine MHC class II $\mathrm{Ag}^{\mathrm{g} 7}$ molecule is a known mediator of $\beta$ cell-autoreactive CD4 T cell responses. One important $\beta$ cell autoantigen targeted by CD $4 \mathrm{~T}$ cells in NOD mice is that recognized by the previously identified BDC-2.5 clone. The BDC- 2.5 clone recognizes a peptide derived from an unknown $\beta$ cell granule protein. The authors used the BDC- 2.5 clone to screen a recombinatorial peptide library in order to identify a ligand that mimics the natural antigen (designated as a "mimotope"). A strong agonist peptide was selected solely on the basis of its biologic activity without regard for the affinity of the peptide/Ag7 complex for the BDC-2.5 T cell receptor (TCR). The availability of soluble 


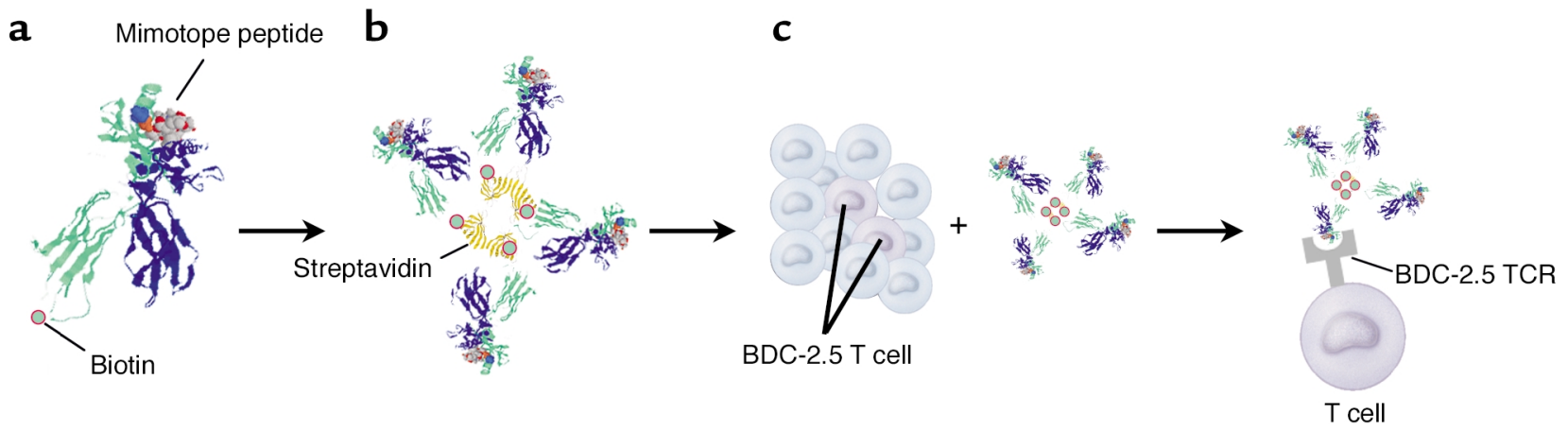

\section{Figure 1}

Tetramer technology used to enumerate a diabetogenic CD4 ${ }^{+} \mathrm{T}$ cell clonotype (designated BDC2.5) in autoimmune diabetes-prone NOD mice. A mimotope peptide structurally similar to the native peptide antigen processed from a pancreatic $\beta$ cell granule protein is presented by the NOD H2-Ag7 MHC class II molecule (a). The MHC class II $\alpha$ chain is depicted in green, the $\beta$ chain in blue, and the mimotope peptide in grey/red space fill representation. The $\alpha$ chain of the peptide-associated $\mathrm{H} 2-\mathrm{A}^{\mathrm{g}}$ complexes are biotinylated, allowing tetramer formation by binding four such molecules to streptavidin (b). Such a reagent allows detection of T cells with the BDC2.5 specificity in the anatomical site of choice (c). Tetramer crystal structure courtesy of Luc Teyton (The Scripps Research Institute, La Jolla, California, USA).

$\mathrm{A}^{\mathrm{g} 7}$ molecules then allowed the authors to construct a fluorochromelabeled tetramer complex containing a selected agonist peptide (Figure 1). As described earlier, the staining of naive CD4 T cells with MHC multimers has been highly problematic. Hence, it was significant that the tetramer technology employed by Stratmann et al. overcame these problems, facilitating an accurate, quantitative, and qualitative characterization of how the BDC-2.5 clonotype contributes to IDDM.

Stratmann et al. (1) demonstrated that, not surprisingly, the BDC-2.5 clonotype was positively selected in the thymus of NOD mice and expanded to higher levels in the periphery. However, the highest numbers of this clonotype were observed in the pancreatic lymph nodes. The proportion of CD4 $\mathrm{T}$ cells in peripheral lymph nodes with the BDC-2.5 antigenic specificity $(0.25 \%)$ was several logs higher than the usual frequency of $T$ cells with a given antigen specificity. Importantly, a small but definable population of BDC-2.5 cells was detected in the pancreatic islets. This new generation tetramer reagent also allowed the authors to isolate a series of $\mathrm{T}$ cells with BDC- 2.5 antigen specificity. It also revealed that these cells are diverse in terms of their TCR repertoire and vary in their strength of antigen recognition.

The result that was most surprising to these commentators was that the tetramer revealed the presence of BDC-2.5 T cells in the B6. $2^{\mathrm{g}^{7}}$ and nonobese resistant (NOR) mouse strains, which are both IDDM resistant, but which express the diabetogenic NOD $\mathrm{H}_{2} \mathrm{~g}^{7}$ haplotype (1). Although the $\mathrm{H}^{2} \mathrm{~g}^{7}$ haplotype is the strongest contributor to IDDM development in NOD mice, it has been well established that multiple other non-MHC genes (described by Stratmann et al. as "background genes") are also essential in the development of this disease. Based upon their findings, the authors concluded that the $\mathrm{H} 2^{\mathrm{g} 7}$ haplotype is the only genetic element required for selection and emergence of autoreactive $T$ cells without requiring other diabetogenic loci from the NOD genome. Because the B6.H2 $2^{\mathrm{g} 7}$ and NOR mice remain IDDM-free, the authors concluded that the role of non-MHC genes is to peripherally regulate the activation of pathogenic $\mathrm{T}$ cells following their emergence. However, we suggest that caution should be employed in extrapolating results based on a single CD4 clonotype to the overall issues of how MHC and non-MHC genes interactively contribute to IDDM susceptibility or resistance.

Many other CD4 $\mathrm{T}$ cells that respond to antigens differing from those recognized by the BDC- 2.5 clone also contribute to IDDM in NOD mice. While the study by Stratmann et al. (1) provides insight into how MHC and non-MHC genes regu- late the development of $\mathrm{T}$ cells with BDC-2.5-like reactivity, several issues must be taken into account when considering the global applicability of their findings. Indeed, another recent study found that non-MHC genes in NOD mice contributed to defects that allowed CD4 $\mathrm{T}$ cells that recognize another pancreatic $\beta$ cell protein to escape negative selection (2). Another question to consider is whether the native antigen recognized by $\mathrm{T}$ cells exhibiting a BDC- 2.5 reactivity pattern is expressed intrathymically in the same way as some other diabetogenic antigens, such as insulin. Furthermore, the authors' data indicate that while BDC- $2.5 \mathrm{~T}$ cells are present in IDDM-resistant NOR mice, their levels are lower than in the closely related NOD strain. This suggests that some non-MHC genes present in NOR mice may contribute to a more limited selection of such effectors. As noted by Stratmann et al., autoreactive CD8 $T$ cells are also essential contributors to the spontaneous development of IDDM in NOD mice, and the NOR strain exerts a non-MHC gene function that limits the development of at least one of these pathogenic CD8 $\mathrm{T}$ cell clonotypes (3).

While we are still at an early stage in understanding the complexities of interactions between MHC and nonMHC genes that underlie IDDM development in both humans and rodent models, the authors have identified a powerful new means to 
monitor and characterize CD4 $\mathrm{T}$ cell populations contributing to this disease. Such reagents may ultimately prove to be of use in monitoring the efficacy of intervention protocols that may inhibit progression to overt
IDDM in humans at risk for this debilitating disease.

1. Stratmann, T., et al. 2003. Susceptible MHC alleles, not background genes, select an autoimmune $\mathrm{T}$ cell reactivity. J. Clin. Invest. 112:902-914. doi:10.1172/JCI200318337.
2. Lesage, S., et al. 2002. Failure to censor forbidden clones of CD4 T cells in autoimmune diabetes. J. Exp. Med. 196:1175-1188.

3. Verdaguer, J., Amrani, A., Anderson, B., Schmidt, D., and Santamaria, P. 1999. Two mechanisms for the non-MHC-linked resistance to spontaneous autoimmunity. J. Immunol. 162:4614-4626

\title{
15-deoxy- $\Delta^{12,14}$-PG $\mathbf{J}_{2}$ : endogenous PPAR $\gamma$ ligand or minor eicosanoid degradation product?
}

\author{
William S. Powell \\ Meakins-Christie Laboratories, Department of Medicine, McGill University, \\ Montreal, Quebec, Canada
}

\begin{abstract}
15-Deoxy- $\Delta^{12,14}$-prostaglandin $\mathrm{J}_{2}\left(15 \mathrm{~d}-\mathrm{PG} \mathrm{J}_{2}\right)$ affects gene transcription by activating PPAR $\gamma$ and by covalent addition to transcription factors and signaling molecules, However, it is not known whether the high concentrations of $15 \mathrm{~d}-\mathrm{PGJ}_{2}$ required for these responses are consistent with physiological levels. A new study (see the related article beginning on page 945 ) suggests that in vivo $15 \mathrm{~d}-\mathrm{PGJ}_{2}$ levels are actually several orders of magnitude below the levels required to induce many of the biological effects attributed to this molecule.
\end{abstract}

\section{J. Clin. Invest. 112:828-830 (2003). doi:10.1172/JCI200319796.}

Over the past several years there has been increasing interest in the prostaglandin $\mathrm{D}_{2}$-derived $\left(\mathrm{PGD}_{2}-\right.$ derived) product 15 -deoxy- $\Delta^{12,14}-\mathrm{PGJ}_{2}$ (15d-PGJ $)$ (Figure 1). This substance was first identified in 1983 as a degradation product of $\mathrm{PGD}_{2}$, formed after incubation for extended periods of time in the presence of albumin (1). $15 \mathrm{~d}-\mathrm{PGJ}_{2}$ attracted relatively little attention until 1995, when Forman et al. (2) and Kliewer et al. (3) independently reported in Cell that it is capable of activating the transcription factor PPAR $\gamma$. This finding was of considerable interest because the endogenous ligand for PPAR $\gamma$ was unknown, in

\footnotetext{
Address correspondence to: William S. Powell, Meakins-Christie Laboratories and Department of Medicine, McGill University, 3626 St. Urbain Street, Montreal, Quebec H2X 2P2, Canada. Phone: (514) 398-3864 ext. 094071; Fax: (514) 398-7483;

E-mail: William.Powell@McGill.ca.

Conflict of interest: The author has declared that no conflict of interest exists.

Nonstandard abbreviations used: prostaglandin $\mathrm{D}_{2}\left(\mathrm{PGD}_{2}\right)$; 15 -deoxy- $\Delta^{12,14}$ $\mathrm{PGJ}_{2}\left(15 \mathrm{~d}-\mathrm{PGJ}_{2}\right)$; the concentration of agonist that elicits $50 \%$ of the maximal response $\left(\mathrm{EC}_{50}\right)$.
}

spite of the availability of a number of pharmacological agonists that are used in the treatment of type 2 diabetes because of their ability to enhance sensitivity to insulin. The hypothesis that $15 \mathrm{~d}-\mathrm{PGJ}_{2}$ fulfilled this role was thus very attractive, and $15 \mathrm{~d}$ $\mathrm{PGJ}_{2}$ is often referred to as an endogenous PPAR $\gamma$ ligand. For this to be correct, $15 \mathrm{~d}-\mathrm{PGJ}_{2}$ would have to act at concentrations compatible with its physiological levels. Bell-Parikh et al. now report a highly sensitive and specific assay that they have used to address this question (4).

\section{Conversion of $\mathrm{PGD}_{2}$ to $15 \mathrm{~d}-\mathrm{PG} \mathrm{J}_{2}$}

The synthesis of prostaglandins is initiated by activation of phospholipase $A_{2}$, resulting in the release of arachidonic acid, which is then converted by cyclooxygenases to $\mathrm{PGH}_{2}$. This unstable intermediate is converted enzymatically to a series of biologically active prostanoids, each of which has its own selective receptor(s). $\mathrm{PGD}_{2}$ is formed by the actions of hematopoietic and lipocalin-type $\mathrm{PGD}_{2}$ synthases and is metabolized enzymatically to
$11 \beta-\mathrm{PGF}_{2 \alpha}$ and 13,14-dihydro-15keto-PGD 2 . Alternatively, $\mathrm{PGD}_{2}$ can undergo chemical dehydration, losing a molecule of water to form the cyclopentenone prostaglandin $\mathrm{PGJ}_{2}$. $\mathrm{PGJ}_{2}$ can then undergo further dehydration by loss of the 15-hydroxyl group, which, coupled with migration of the 13,14-double bond of $\mathrm{PGJ}_{2}$ results in the formation of $15 \mathrm{~d}-\mathrm{PGJ}_{2}$ (Figure 1). These reactions are promoted by albumin but proceed at a relatively slow rate compared to the very rapid formation of PGs from $\mathrm{PGH}_{2}$ by prostanoid synthases. There is no evidence for the enzymatic formation of any of these cyclopentenone PGs, and this lack of evidence is one of the factors that has brought into question their physiological relevance.

\section{$15 d-P G J_{2}$ as a PPAR $\gamma$ ligand}

The two papers published in Cell in 1995 sparked considerable research on the biological effects of $15 \mathrm{~d}-\mathrm{PGJ}_{2}$. As it has been considered to be an endogenous ligand for PPAR $\gamma, 15 \mathrm{~d}-\mathrm{PGJ}_{2}$ has been employed in many studies on the role of this transcription factor and in most cases shown to have effects similar to those of synthetic PPAR $\gamma$ ligands. This raised the possibility that $15 \mathrm{~d}-\mathrm{PGJ} \mathrm{J}_{2}$ could be a physiological regulator of processes affected by PPAR $\gamma$, including adipocyte differentiation and regulation of glucose levels (5). In addition, there has recently been considerable interest in the role of PPAR $\gamma$ in regulating the inflammatory response, as $15 \mathrm{~d}-\mathrm{PGJ}_{2}$ and other PPAR $\gamma$ agonists inhibit the expression of a variety of proteins with proinflammatory properties, including cyclooxygenase-2, iNOS, and a variety of cytokines (6). These effects appear to be mediated by inhibitory effects on various transcription factors, including NF- $\mathrm{KB}$, activator protein-1 (AP-1), and signal transducer and activator of transcription-1 (STAT-1). This has led 